\title{
LA LIBERTAD DE CÁTEDRA DE LAS UNIVERSIDADES CON IDEARIO RELIGIOSO: OBJECIONES Y RESPUESTAS
}

\author{
ACADEMIC FREEDOM IN RELIGIOUSLY-AFFILIATED UNIVERSITIES: \\ OBJECTIONS AND ANSWERS
}

\section{Raúl MAdrid RamíreZ}

\begin{abstract}
RESUMEN: El tema de este trabajo, o su perspectiva más bien, será la libertad de cátedra en las universidades con ideario religioso. La perspectiva del análisis intenta configurar un foco de sentido desde el cual abordar la cuestión de la autonomía de este tipo de centros académicos, que hoy entran en crisis de la mano del concepto mismo de universidad. El problema específico que se abordará tiene dos fases: la libertad de la universidad para (a) contratar profesores dispuestos a cumplir las exigencias del ideario institucional en su desempeño, y por lo tanto la versión inversa: rechazar a aquellos que manifiesta y reiteradamente se opongan a dicha declaración de principios. Junto a ello, (b) se discutirá la capacidad real de que disponen dichas universidades a la hora de generar para sus académicos un espacio de libertad que sea cualitativamente coherente con la concepción de la verdad declarada en los postulados fundacionales. Detrás de la garantía de libertad de cátedra deben considerarse dos cuestiones previas: la existencia o inexistencia de una noción única y hegemónica de universidad, y el concepto de libertad que se encuentre vigente en la sociedad, cuestión que se relaciona directamente con las estrategias de dominación del discurso publico.
\end{abstract}

Palabras clave: Libertad de cátedra, autonomía académica, universidades con ideario.

ABSTRACT: The theme of this paper, or rather its perspective, is the academic freedom in religiously-affiliated universities, aiming to approach the problem of their autonomy, which today seems to be in crisis, along with the concept of university itself. The specific problem to be addressed has two phases: (a) the freedom of the university to hire professors willing to comply with religious institutional requirements in their performance, and, accordingly, the inverse scenario: to dismiss those who manifestly and repeatedly oppose to said statement of principles; and (b) the real capacity of religiously-affiliated universities to provide a scope of freedom to their faculty, being it qualitatively consistent with the idea of truth that is declared in the founding declarations. Two previous questions must be considered behind the right to academic freedom: the existence or absence of a unique and hegemonic notion of university, and the concept of freedom which is currently valid in the society. This last matter is directly related to the strategies used to dominate public discourse.

Keywords: Academic freedom, academic autonomy, religiously-affiliated universities.

\footnotetext{
* Doctor en Derecho por la Universidad de Navarra. Profesor Titular. Director del Programa de Derecho, Ciencia y Tecnología de la Facultad de Derecho de la Pontificia Universidad Católica de Chile. Código Orcid 0000-0003-4592-6985. Dirección postal: Avda. Libertador Bernardo O’Higgins No 340, Santiago, Chile. Correo electrónico: rmadrid@uc.cl.
} 


\section{ANTECEDENTES}

Se abordarán en este trabajo algunas de las posibles respuestas a cuatro problemas concretos, relacionados con el estatus y la subsistencia de las universidades con ideario religioso en nuestro tiempo. Es preciso advertir, antes de comenzar, que el presente artículo no se orienta a explicar qué alternativas concretas otorga un ordenamiento positivo en específico para elegir caminos de acción en cada una de ellas. El desarrollo tampoco se dirigirá a los principios éticos y jurídicos abstractos que rigen la libertad de las personas o de instituciones (como las universidades), porque estos son perfectamente conocidos, y sería inoficioso repetirlos en un texto de esta naturaleza. El objeto de este trabajo será el diálogo que pueden entablar este conjunto de libertades asociadas a las universidades con ideario religioso, no ya con la modernidad y su desdén por toda proposición supra-empírica, sino con las condiciones culturales de un tiempo radicalmente distinto a la experiencia clásica, escolástica o moderna, como es el tiempo presente. Aunque se tiene en mente principalmente el caso de las universidades católicas, lo dicho en estas páginas es aplicable en general a las universidades con un ideario de este tipo. Así pues, al referirnos al "ideario", debe entenderse su vínculo con alguna religión en particular.

La condición de nuestro tiempo puede ser considerada en varios sentidos como la más singular de la historia de Occidente, en virtud del modo en que la cultura ha terminado acogiendo y multiplicando, a través de la tecnología y lo que Baudrillard denominaba las "supercarreteras de la información", en las que todo es $\mathrm{red}^{1}$, los fundamentos de un pensamiento nihilista que hoy en día domina casi todos los parámetros del mundo moral, social, jurídico y político. No cabe aquí desarrollar con detalle cómo se ha producido este resultado, pero la indudable existencia de criterios hermenéuticos muy distintos incluso de aquellos utilizados por los contradictores tradicionales de las universidades con ideario, obliga a repensar el modo mismo de hacer primar hoy una libertad que, a los ojos de muchos contemporáneos, no solo es inútil, sino intrínsecamente perniciosa y hostil para la declaración de principios postmoderna. Esto quiere decir que, dentro de poco, si no ocurre ya, se intentará utilizar el Derecho mismo para suprimir determinadas instituciones y su aproximación a la verdad, en virtud de que formulan, declaran o sostienen proposiciones morales materiales, que a la vez pretenden ser universales. Esto significa que, en nuestro tiempo, se produce una enorme paradoja: las instituciones democráticas y los agentes políticos y culturales, el sistema educativo y los medios de comunicación tecnológica, los actores civiles (como las ONGs) y los organismos internacionales, todos ellos en su conjunto y de manera sostenida, declaran y consagran como parte del ideario de los derechos humanos la libertad de asociación, de contratación, de expresión y de cátedra². Sin embargo, en los hechos, todas estas libertades se ven cada vez más selectivamente conculcadas, como fruto de un largo proceso de ideologización de las bases culturales de Occidente, pero también por causa de una exitosa estrategia de dominación del discurso público, que hoy rinde sus

\footnotetext{
1 Baudrillard (1987) p. 10.

2 Véase por ejemplo, Chicago Principles: Report of the Committee on Freedom of Expression. University of CHICAGo. Disponible en: https://freeexpression.uchicago.edu. Fecha de consulta: 18 de febrero de 2019.
} 
frutos en la mayoría de los países occidentales ${ }^{3}$. Esta estrategia se relaciona también con nuevas concepciones de la "justicia académica"

La cuestión de dar respuesta a las preguntas que nos ocupan es más compleja de lo que parece, precisamente por causa de la variación en los parámetros culturales a que hacíamos referencia antes. Se trata de preguntas jurídicas, que hubieran merecido una respuesta también jurídica, que hoy sin embargo no es posible, o al menos no es enteramente posible. Esto no quiere decir, ciertamente, que no puedan resolverse en atención a un determinado derecho escrito. El problema no dice relación con la existencia de normas que ofrezcan en Chile, o en cualquier parte del mundo, certeza sobre los comportamientos; ni siquiera se relaciona con la existencia de intérpretes de dichas normas que equivoquen el camino, y las lean en un sentido erróneo, inapropiado o incluso interesado: jueces, administradores, etc. El verdadero problema radica en la creciente imposibilidad de distinguir entre el Derecho y la política, o más bien: cómo, en función de la política, se puede hoy desdeñar el Derecho5 Esta opinión, como se verá a continuación, hace referencia a criterios postmodernos, en que las diversas instituciones adquieren una dimensión política radical, merced a la naturaleza de sus postulados. Hay varias razones para explicar esto. Una es decir que se ha producido una deconstrucción del binomio Derecho-poder. Esto parece ser un hecho, y su desarrollo merecería por sí solo una monografía independiente. Otra razón, es la analogía con la postverdad, es decir, con la idea de que los hechos objetivos influyen menos en la formación de la opinión pública, que los llamamientos a las emociones y creencias personales ${ }^{6}$. Así, la verdad, destituida de su lugar junto al conocimiento, desde el punto de vista cultural comienza a ser desplazada por la credibilidad. El Derecho ocuparía en esta analogía el lugar de los hechos: no influiría en la decisión política, que buscaría ser "creíble", es decir, responder a lo que una determinada audiencia espera de ella. La pregunta que surge a continuación es cuál es esa audiencia, en el esquema cultural de la postverdad. Cuando se trata de Derecho y de normas jurídicas, lo normal hubiera sido esperar que la audiencia a que hacemos referencia fuera la comunidad letrada, es decir, la comunidad que puede dar razón técnico-jurídica de la decisión o resolución que ha tomado la autoridad, y que tiene relevancia normativa. En los nuevos paradigmas culturales de las sociedades occidentales, sin embargo, esto dista mucho de ser así. La verdadera audiencia contemporánea -desde el punto de vista de su eficacia- son las redes sociales, unidas a los medios de comunicación, los cuales cada vez más se parecen, por su parte, a una red social. Ellos son los que dictaminan lo que es "creíble", y por lo tanto lo que es jurídicamente aceptable.

Evidentemente, la "credibilidad" se encuentra asociada aquí a la cantidad de espacio público que se domina. El espacio público contemporáneo representa una versión horizontal del poder, en sentido foucaultiano: el poder se presenta como una relación, es decir, como un término aplicable a un conjunto de relaciones en las que hay conflictos de

\footnotetext{
3 La corrección política se remite a una política cultural. Véase FAIRCLOUGH (2003) p. 20.

4 KORN (2014).

5 Véase por ejemplo el argumento de Habermas (1993) p. 329.

6 Oxford Dictionaries, voz "post-verdad". Disponible en: https://en.oxforddictionaries.com/definition/posttruth. Fecha de consulta: 18 de febrero de 2019.
} 
intereses, metas, preferencias, etc., todas ellas enfrentadas entre sí, y consiguiendo sus objetivos a expensas de las otras ${ }^{7}$. La relación de fuerzas quiere decir que a la fuerza le pertenece esencialmente la relación con otra fuerza: "la fuerza no existe en singular, no hay fuerza en singular [es decir, vertical, en sentido tradicional]. Toda fuerza es relación con otra fuerza. Esto quiere decir que la fuerza es fundamentalmente el elemento de una multiplicidad y que no puede ser pensada fuera de lo múltiple, que no hay fuerza una. Es incluso en este sentido que la fuerza no tiene más objeto ni sujeto que la fuerza. Esto no quiere decir que la fuerza sea su propio objeto y su propio sujeto, tiene por objeto otra fuerza o, lo que es lo mismo, que una fuerza tiene por sujeto a otra fuerza" ${ }^{8}$. De este modo, el poder se transforma en una microfísica - un espacio de relación entre infinitos actores de igual rango-, que se articula por medios intangibles, como es el que proporcionan las nuevas tecnologías de la información. Este parece ser el verdadero motor de la dialéctica social.

Lo que acabamos de revisar, me parece, debe ser tenido en cuenta necesariamente a la hora de preguntarse por cuáles son las libertades que deben esperar hoy en día, realmente, las universidades con ideario, más allá de lo que digan las normas positivas y las palabras de buena crianza de los políticos. Voy a centrarme específicamente en aquellas casas de estudio que mantienen declaraciones de principios que van en contra de las corrientes culturales contemporáneas, porque las otras no representan verdaderamente un problema: son “creíbles", y se les concede la ansiada "neutralidad" sin mayor discusión. ¿Qué validez tiene en nuestro tiempo el ideario de las universidades contraculturales como criterio de corrección de sus actos institucionales, y de los actos de sus académicos? Me parece que esa validez depende de que dichos centros de educación superior consigan de hacer ponderar en su favor las objeciones formuladas desde las corrientes opuestas, que parecen haber dominado la escena pública. Las objeciones que yo veo son las siguientes:

\section{LAS UNIVERSIDADES CON IDEARIO DISCRIMINAN ARBITRARIAMENTE POR SU MISMA EXISTENCIA, Y DEBEN POR LO TANTO SER SUPRIMIDAS}

Esta objeción es probablemente la más radical, y de momento no se ha planteado con pretensión jurídica final, lo que no quiere decir que no pueda ocurrir en el futuro, especialmente en contextos de sociedades multiculturales donde los ciudadanos casi no comparten presupuestos vitales ni morales. Consiste, como adelantábamos antes, en la idea de que las personas y las instituciones que sustentan concepciones universales y materiales del bien moral se situarían per se fuera de las reglas democráticas de convivencia, porque tal presupuesto atentaría intrínsecamente contra la dignidad de los terceros, en la medida en que declaran como "malas" o "impropias" ciertas decisiones morales que algunos individuos o grupos adoptan como preferencias o formas de vida. Esta interpretación está vinculada con aquellas doctrinas que sostienen en último término que la afirmación de la verdad en sentido universal constituye un acto de violencia. Un modo en que esta idea se canaliza

\footnotetext{
Philp (1983) p. 32.

8 Deleuze (2014) p. 66.
} 
es la insistencia en que la universidad pública debe ser laica, porque ello es un requisito sine qua non de la democracia'.

El principal y más refinado exponente de esta tesis en el siglo XX es Jacques Derrida. En el contexto de su obra, la metafísica, y todas las ciencias derivadas que establecen juicios materiales y universales como verdaderos, ejercerían una violencia originada en y por el acto mismo de la decisión que implica la formulación de ese juicio. Porque para Derrida y sus epígonos, toda decisión supone a la vez una negación y una exclusión ${ }^{10}$. Esta tesis ha traducido institucionalmente en el ámbito académico, mediante mecanismos como los de la llamada "corrección política", en la cual no se puede sostener ninguna opinión que incomode a los colectivos considerados como minorías, por muy fundada científicamente que pueda estar.

En el caso de las universidades que pertenecen o son afines a la Iglesia Católica, se produce un efecto perverso, por cuanto algunos de estos preceptos se ven cuestionados públicamente en virtud de la exitosa intermediación de los medios de comunicación y las redes sociales, que callan, adulteran o reinterpretan ideológicamente afirmaciones o comentarios de las autoridades eclesiásticas. De esta forma se configura una opinión creciente en la audiencia de que la catolicidad no consiste en absoluto en "juzgar" la bondad o maldad de los actos, sino solo en "amar", lo que deja abandonada a su suerte a las universidades y a los académicos que insistan en explicar los principios de moral natural relativos a tales preceptos.

Así pues, la cuestión de fondo es qué razones pueden esgrimir las universidades católicas para que se admita que promuevan sus creencias últimas acerca de la condición humana mediante el trabajo universitario. Como plantea Carlos Peña, ¿acaso no le es suficiente, a la Iglesia Católica, por ejemplo, con las Iglesias y los medios de comunicación de que dispone? ¿No ocurrirá con la expresión "universidad católica" lo que, según Heidegger, ocurre con la expresión "filosofía cristiana", que es un oxímoron, como "hierro de madera"?"11 Esta es una pregunta que los miembros de las universidades católicas tienen por fuerza que ser capaces de responder ${ }^{12}$, si desean asegurar su libertad de asociación en torno al análisis y la docencia de ciertas verdades fundamentales, en medio de un mundo que reclama como requisito de la democracia la ausencia de verdad.

\section{SEGUNDA OBJECIÓN. LAS UNIVERSIDADES CON IDEARIO TIENEN UN DEFECTO EPISTEMOLÓGICO ESENCIAL: NO SON NEUTRALES, Y POR LO TANTO REPRESENTAN UN INTERÉS PRIVADO, QUE NO SATISFACE LO QUE SE ESPERA DE UNA UNIVERSIDAD}

Ya en 1915, los redactores de la primera Declaración de la American Association of University Professors (AAUP) advertían que las instituciones privadas actúan de modo dife-

\footnotetext{
9 MOCHÓN (2019).

10 Derrida (2004) p. 49.

11 El Cardenal Newman responde esta problemática de modo excelente, especialmente en los discursos 4 y 8 . NEWMAN (2016) pp. 69-84 y 125-138.

12 Peña (2018) p. 107.
} 
rente de las universidades del Estado, por cuanto estas últimas estarían comprometidas con el conocimiento, mientras que las otras obrarían "según los que sean sus puntos de vista", usando el college como "instrumento de propaganda" de ellos. Estas instituciones no aceptarían los principios de libertad de investigación, de opinión ni de enseñanza; siendo su propósito no el avance del conocimiento por la investigación sin restricciones y la discusión libre por académicos imparciales, sino más bien el apoyar la difusión de opiniones emitidas por sujetos no académicos, que proporcionan los fondos de la institución. La actitud coherente con tal premisa es negar a estas instituciones el valor de un estatuto sustentable, afirmando que su objeto es sólo el proselitismo, no el conocimiento racional o intersubjetivo, que sería patrimonio exclusivo de su paradigma puramente empírico. Así lo dice expresamente Dewey, al afirmar que al discutir las cuestiones que se resumen en la expresión 'libertad de cátedra', es necesario distinguir entre las universidades propiamente dichas, y aquellos cuerpos docentes cuyo objetivo primario es inculcar un conjunto determinado de hechos e ideas. Las primeras buscan descubrir y comunicar la verdad, y hacer de la audiencia mejores jueces de la verdad y mejores aplicadores de ella en los asuntos cotidianos. Los segundos tienen por objetivo el perpetuar una cierta manera de ver las cosas de un grupo de personas. Su objetivo es más bien disciplinar más que formar, no tanto a expensas de la verdad, sino de tal manera que se conserve lo que ya es considerado verdadero por un grupo considerable de personas ${ }^{13}$. Dewey no niega el derecho de cualquier institución religiosa, política o incluso económica de regentar centros de educación superior desde un punto de vista jurídico ${ }^{14}$; su argumento es más bien de naturaleza moral: tales instituciones no podrían alcanzar la verdad, que les estaría vedada por el hecho de sustentar determinadas proposiciones que son consideradas ex ante como verdaderas. Serían, por decirlo así, creaciones esperpénticas, pero lícitas, en base justamente a la libertad que, como un trasfondo, constituiría el verdadero horizonte de significado de la acción humana. Este argumento subsiste hoy en día como crítica a este tipo de centros, en la medida en que su objetivo (privado) es distinto del que se puede encontrar en las universidades "laicas" o "neutrales". Enfatizan su vínculo con una determinada religión (en el caso de las confesionales), su intencionalidad apostólica. Andreescu cita por ejemplo a la Universidad de Notre Dame, que declara estar tanto al servicio de la fe como del conocimiento científico ${ }^{15}$. La objeción se centra pues en la supuesta ambivalencia de estas entidades entre la adhesión a valores "sectarios" o privados, y la búsqueda del éxito académico en sentido propio ${ }^{16}$.

La universidad secular moderna, es decir, la universidad que surge en el S. XIX, tanto la napoleónica como la humboldtiana, en su versión profesional y científica, suponen que hay un lugar neutral en el que todos los puntos de vista pueden converger, y este lugar neutral sería la racionalidad ${ }^{17}$. El ideal de la universidad secular moderna sería erigir un piso neutral donde todos los puntos de vista pudieran refugiarse a condición de ser racio-

13 DeWey (1902) p. 1.

14 Dewey (1902) pp. 1-2.

15 Andreescu (2008) p. 166.

16 Ingram (1986) p. 300.

17 Véase Simon (1972) pp. 217-233. 
nales, es decir, se repudiará por completo el carácter confesional de la universidad escolástica ${ }^{18}$. La universidad sería, en consecuencia, un ámbito donde se practica la racionalidad entendida como una actitud que antecede a toda respuesta posible y que, por lo mismo, sería neutra como advierte Hollinger, la universidad de investigación, bajo la idea de la Wissenschaft, se refería a una verdad descubierta, no revelada ${ }^{19}$. En este contexto, las universidades con ideario estarían imposibilitadas de cumplir con esta exigencia, porque su punto de partida ex ante impediría el encuentro con la racionalidad, descrita en términos modernos. No serían, propiamente, por lo tanto, universidades, sino centros de adoctrinamiento que deben ser eliminados o bien "ocupados", en caso de que tengan una alta relevancia social o institucional.

Por otro lado, cabe preguntarse si existe ese lugar neutral, esa neutralidad. Si se observa las universidades pretendidamente neutrales, encontramos que, de hecho, están dominadas por corrientes de pensamiento que son en su mayoría opuestas a las tesis de las universidades con ideario. Es decir, hay fundadas sospechas de que el recurso a la neutralidad es en realidad una estrategia de dominación para ocupar espacios de poder en el ámbito académico: el modelo de racionalidad que esgrime la universidad secular moderna parece ser una forma de ideología encubierta. En el momento en que esta racionalidad se escinde de la idea de verdad, la segregación de las universidades con ideario se transforma en, por llamarlo de algún modo, postmoderna, y la actividad académica comienza entonces a estructurarse en torno al poder $^{20}$. La universidad se ha transformado en nuestro tiempo, ha pasado de ser un lugar destinado a la verdad, presidido por una especie de concordia en la verdad -en sentido aristotélico-, a constituir una suerte de arena en la que se enfrentan distintos bandos, de tal manera que las instituciones de educación superior contemporáneas terminan esgrimiendo la pureza metodológica y la neutralidad racional como un arma para aplastar a los puntos de vista minoritarios, para perseguirlos incluso fuera del ámbito académico. Se unen al discurso oficial de los paradigmas culturales propugnados por los medios de comunicación y las redes sociales, pero con una pátina intelectual que busca justificar la superioridad metodológica y moral. Esta actitud, por lo demás, no es nueva desde un punto de vista material. Ocurrió en Estados Unidos a principios del siglo XX, cuando las diversas ortodoxias se enfrentaron en facultades de humanidades logrando acorralar a un bando u otro, utilizando el recurso de la libertad de cátedra, que se estrenaba desde hacía algunos años ${ }^{21}$; ocurrió también en el momento en que los profesores norteamericanos expulsaron de la universidad alemana de la postguerra a todos los académicos formados en el modelo humboldtiano, con el argumento de haber sido proclives de un modo u otro al nacionalsocialismo, reemplazándolos por profesores formados en la misma tendencia de Humanidades antes mencionada ${ }^{22}$.

\footnotetext{
8 Paulsen (1906) p. 54

19 Hollinger (1987) p. 37 ss.

20 Altbach (1999) pp. 107-24.

21 Furner (1975) p. 8.

22 Tsvetkova (2013) p. 89.
} 
Una universidad católica, por el contrario, debiera sostener que el pluralismo alcanza a la misma idea de racionalidad: la racionalidad no sería neutral en sí misma, sino que habría varios tipos de racionalidad: se trataría de un concepto analógico. Una racionalidad sensible al misterio sería también una forma de racionalidad con derecho a existir en el espacio público, una racionalidad abierta a todos los aspectos de la existencia humana. Habría razones, por llamarlas así, epistemológicas, diría una universidad católica, para que no se ponga en cuestión su índole universitaria y su vocación racional. Esta idea -sobre la base de la cual podría defenderse la existencia de una universidad católica- puede ser considerada en cierto sentido una idea extremadamente moderna: la razón auscultándose a sí misma descubre, de pronto, que ella tiene varias versiones posibles, que siempre hay un punto ciego en el que descansa, y que ciertos tipos de racionalidad desconocen, mientras que otras, como las universidades católicas o con ideario, muestran o pueden mostrar por el contrario cierta apertura hacia él ${ }^{23}$.

En lo relativo a la pregunta sobre qué razones puede esgrimir una universidad católica para que se le permita existir y usar de su autonomía institucional, siguiendo el argumento de Carlos Peña pueden pensarse cuatro ${ }^{24}$ : (a) Una razón es utilitaria, el sistema universitario va a estar mejor con universidades católicas que sin ellas (esto es evidente en el caso de Chile. En el caso de Chile, la Universidad Católica es prácticamente la mitad de la tradición del sistema universitario, entonces un puro criterio utilitario lo llevaría a usted a decir que es mejor que sobreviva la Universidad Católica a que no exista); (b) Pero también hay un criterio epistemológico: es incoherente un modelo de búsqueda única de la verdad que subyace en la universidad secular, y entonces la universidad católica debiera decir, mire, en realidad desde el punto de vista epistemológico, el pluralismo alcanza a la misma idea de racionalidad. En consecuencia, porque somos pluralistas, tenemos que permitir que la diversidad se exprese no solo al interior de la universidad secular, como manifestaciones de una única racionalidad, sino que en el sistema de educación superior convivan varias ideas de racionalidad; (c) existiría en primer lugar una razón política: Si se rechaza la existencia de universidades no seculares, se estaría sacrificando, en un futuro posible, las creencias de las minorías. Es posible que existan minorías con ideas peculiares, extrañas o excéntricas, que a la mayoría le parezcan exóticas, erradas o incluso absurdas, pero que podrían enriquecer la cultura pública. Impedir el desarrollo de esas ideas tiene como efecto dañar la democracia. Este argumento, me parece, es ilustrativo de cómo utilizar las categorías postmodernas para defender lo tradicional, pues está basada en la concepción del marketplace of ideas. (d) Finalmente, el argumento de la libertad religiosa. En un Estado moderno y democrático la libertad académica debe coexistir con la libertad religiosa y la libertad religiosa debe suponer el derecho de los ciudadanos a asociarse en base a sus creencias finales acerca de la condición humana y transmitirla a las nuevas generaciones mediante el sistema educativo. Si esto se prohíbe, en realidad, se concebiría la libertad religiosa como un simple derecho individual, lo que no resulta razonable desde un punto de vista ni jurídico ni conceptual.

\footnotetext{
3 Peña (2018) p. 113.

24 PEÑa (2018) p. 114-5.
} 


\section{TERCERA OBJECIÓN. LAS UNIVERSIDADES CON IDEARIO NO PUEDEN LIMITAR LA LIBERTAD DE CÁTEDRA DE SUS ACADÉMICOS POR CAUSA DE SUS PRINCIPIOS}

Este es el sentido de lo que argumenta la Declaración fundacional de la AAUP en 1915: las universidades con ideario no dispondrían de potestad moral para limitar la libertad de los académicos: "Los Consejos de tales universidades carecen de autoridad moral para limitar la razón o la conciencia de ningún profesor. Toda exigencia en este sentido queda desestimada porque el público contribuye y otorga su apoyo no a la propaganda, sino a la mantención de instituciones de educación no partisanas. Así, toda universidad que establezca restricciones a la libertad intelectual de sus profesores se auto-proclama una institución privada, y debe ser conocida como tal cuando solicite fondos, y el público debiera ser advertido de que dicha institución carece de derecho para ello ${ }^{25}$. En España, por ejemplo, el krausismo pretendía que fuera inviolable el profesor en la expresión de su pensamiento bajo la salvaguardia de la libertad científica y de su conciencia moral, de lo que se sigue que la restricción del ideario sería ilegítima, porque en definitiva la libertad de cátedra se configuraría solo como una libertad frente al Estado, la cual garantizaría la libre expresión del profesor funcionario en el ámbito de la enseñanza pública superior, sin considerar otros criterios ${ }^{26}$.

Este problema de la libertad de cátedra considerada como un absoluto es, probablemente, la objeción más compleja de responder de cara a la nueva sensibilidad, porque cualquier limitación parece dirigirse directamente contra la libertad de conciencia individual, que constituye el núcleo más sagrado de la modernidad, y también del postestructuralismo, aunque por razones profundamente distintas en cada caso. Para poder abordarla correctamente es necesario comprender primero que la noción de libertad de cátedra es también un concepto análogo, no unívoco, como parece defender gran parte de la doctrina jurídica contemporánea ${ }^{27}$. La definición estándar contemporánea de libertad de cátedra en sentido profesional (es decir, no como expresión de la autonomía universitaria) la entiende como una potestad atribuida a los académicos para investigar en cualquier área del conocimiento, y para emitir opiniones científicamente sustentables en su calidad de miembros de una comunidad universitaria, sin que ello traiga sanciones de especie alguna por parte del Estado, de las autoridades universitarias ni de los propios pares $^{28}$. Se trata de un espacio de libertad que correspondería por derecho propio a cada académico, que le sería irrenunciable e inalienable, a través del cual éste desarrollaría su trabajo de un modo absoluto e idéntico en todos los tiempos y lugares. La libertad de cátedra es vista como una especie de condición de posibilidad a priori para la creatividad intelectual y el avance en la producción de conocimiento. En este contexto, el intento de corregir esta libertad abstracta, perteneciente al profesor, mediante el expediente de una declaración de principios o un ideario propio de la

\footnotetext{
251915 Declaration of Principles, 1. Basis of Academic Authority.

26 Véase Rodríguez (1998) p. 44.

27 Sobre la definición de la libertad de cátedra, Metzger (1978) pp. 96 ss.

28 MAdRid (2018) p. 32.
} 
universidad, resultaría contrario a la misma esencia no solo de la universidad como institución misma, sino al hecho mismo del conocimiento ${ }^{29}$.

Frente a esta fórmula, las universidades con ideario deben hacer un esfuerzo para aclarar el verdadero significado de su conducta, que no constituye en realidad una limitación a la libertad de cátedra, porque dicha libertad, al igual que ningún otro derecho, no es absoluta ni independiente de las circunstancias concretas del caso particular que debe ser juzgado. En otros términos pues, deben demostrar que la corrección en base al ideario no constituye un atentado a la libertad de cátedra ni a la conciencia de los académicos. Esto, me parece a mí en base a dos mecanismos: (a) delimitar exactamente la conducta que se corrige o sanciona, y (b) insistir en que se trata de una condición lícita del contrato laboral. Analicemos esto por separado. La crítica de fondo que puede hacerse a la idea de la libertad de cátedra como un absoluto que pertenece al profesor como si se tratara de una categoría trascendental, sin atención a la universidad en que se desempeña ni a su contexto, es precisamente que responde a una suerte de razón teórica, puramente abstracta, que carece de los instrumentos para hacerse cargo de las situaciones concretas de conflicto de libertades académicas, que debieran resolverse más bien a través del uso de la razón práctica.

Junto a lo dicho, hay que tener en cuenta que en la actualidad, al interior de los Estados pluralistas, que no debieran amenazar sino favorecer la libertad y la diversidad ideológica, la libertad de cátedra, como el resto de las libertades públicas, ha perdido el sentido de un derecho reaccional o de defensa frente a los poderes públicos, pero adquiere en cambio una nueva dimensión como un bien jurídico que demanda aplicación en todos los ámbitos del derecho, implicando a los poderes públicos en su plena realización y extendiendo incluso, su ámbito de aplicación a las relaciones entre particulares. Esto debiera favorecer la existencia de libertades académicas "sectoriales", como la de los católicos, los mormones, etc., las cuales, sin oponerse al Bien Común, desarrollan aspectos propios y peculiares de éste, a menos que se imponga un nuevo tipo de totalitarismo en el discurso público, como parece ocurrir con estrategias de dominación tal como la llamada "corrección política".

\section{El CONTENIDO DEL “RESPETO” AL IDEARIO}

La idea de un espacio de libertad de los académicos es moderna, y surge como consecuencia de la fragmentación de la unidad religiosa y filosófica del medioevo. Cuando las universidades escolásticas entran en crisis, los académicos empiezan a dejar de verse a sí mismos como engranajes de una gran obra global -la Cristiandad-, y comienzan a percibirse al modo de una clase social y política, con características y derechos propios, que se pueden ejercer contra los gobernantes civiles, o contra las autoridades universitarias. Este es el origen de la idea de libertad de cátedra, que es fruto de la abstracción antropológica de la modernidad y de la ilustración, al igual que tantos otros derechos subjetivos de nuestro tiempo.

29 Esto no debe confundirse con el intento de separar la autonomía universitaria del concepto de libertad de cátedra. En Estados Unidos, algunos autores luchan por defender esta última como un derecho del académico, no solo de la institución. Pero ese es un debate distinto del que aquí se aborda, relativo a la idea de libertad de cátedra -ya separada de la autonomía- que es concebida como un derecho abstracto, es decir, sin atender a las especiales circunstancias de cada universidad y de cada académico. Véase sobre lo primero LeE (2015). 
Con frecuencia se ha imputado a la universidad escolástica reprimir la libertad de cátedra de sus académicos ${ }^{30}$. Esto es un anacronismo, y es el mismo argumento que se emplea hoy contra las universidades con ideario, solo han variado las circunstancias. Es un anacronismo porque traslada la idea moderna de espacio de libertad a un ámbito en el que no tiene cabida, sin perjuicio de las restricciones efectivas que se produjeron en el tiempo en comento. No hay en los procesos anteriores al siglo XVIII ni uno solo en que el académico imputado se haya defendido de la actuación de las autoridades esgrimiendo la existencia de un eventual ámbito propio e inviolable ${ }^{31}$. No hay ninguno, porque a nadie se le habría ocurrido ese argumento. De ahí la inutilidad de analizar la dinámica profesores-autoridades en la universidad escolástica desde el punto de vista de lo que técnicamente se entiende hoy por libertad de cátedra.

¿En qué consiste la restricción asociada al ideario? Esto es una cuestión que debe determinarse con total claridad, para evitar las generalizaciones y confusiones que se derivan de la mala comprensión, en muchas ocasiones interesada ideológicamente, de este mecanismo. Normalmente la fórmula que se utiliza es que los académicos que no comparten la "declaración de principios" no deben combatirlo, sino que están obligados a "respetarlo", es decir, acatarlo, considerarlo, ser deferentes con él ${ }^{32}$. Se trata de una conducta que se tributa al mérito y a la autoridad, mientras que la reverencia se ofrece a la dignidad. El respeto supone también obediencia. Se distingue de la consideración porque ésta posee un carácter social, mientras que el respeto se dice en un sentido moral. Así, se considera al hombre de mérito y se respeta al virtuoso. Como dice Barcia: la consideración nos lleva al mundo, el respeto a una casa, y el acatamiento, a un palacio. Por su parte, la reverencia nos conduce a un altar, y la veneración nos pone muy cerca del cielo ${ }^{33}$.

La cuestión jurídica consiste entonces en determinar qué quiere decir "respetar", en el contexto que aquí nos interesa. Para ello, es preciso resolver una cuestión previa, considerada dentro de las preguntas que me corresponde abordar en este trabajo: el ámbito y los temas que deben ser objeto de esta acción aparentemente incierta que se denomina "respeto". Recuerdo, antes de abordar esto, que he centrado mi exposición en las universidades católicas o de inspiración católica, aunque en principio también tendrían cabida en este análisis las denominadas "cristianas", o pertenecientes a credos distintos. No parece aconsejable, de entrada, formular extensos y detallados listados de asuntos o temas sobre los cuales se espera este misterioso "respeto", del cual hablaremos a continuación. Las enumeraciones normativas suelen acarrear más problemas que soluciones, porque se abren a una casuística

\footnotetext{
30 Classen (1981), p. 532.

31 ThijSSEn (1998) p. 91.

32 Por ejemplo, el art. $3^{\circ}$ de la Declaración de Principios de la Pontificia Universidad Católica de Chile dice lo siguiente: "La Universidad requiere fundamentalmente para el cumplimiento de su misión del testimonio de la fe de sus académicos y de sus demás miembros, pero no excluye de su seno a quienes no participan de la fe de la Iglesia, y está obligada al más delicado respeto de sus conciencias. Con todo, la catolicidad institucional de ella exige de los miembros de la comunidad universitaria que estén en esta situación, una necesaria actitud de respeto y apertura hacia los principios que informan a la Universidad y hacia la misión que ella ha recibido de la Iglesia. Quien combatiere esos principios no puede formar parte de esta Universidad”.

33 BARCIA (1950) voces "respeto" y "consideración”.
} 
que puede ser muy inconveniente a la hora de calificar comportamientos concretos de los académicos. Lo más aconsejable es enunciar los principios generales, y otorgar a alguna instancia la evaluación de las situaciones concretas que se produzcan, sin extender innecesariamente los tipos.

Parece razonable considerar que el ámbito cubierto por la restricción debe tener, en principio, dos grandes núcleos: (a) las verdades fundamentales de la fe y (b) los principios primarios y secundarios de la ley natural al menos en lo que se refieren a los preceptos relativos a la conservación de la vida y la integridad física, y a la conservación de la especie, mediante la procreación, crianza y educación de la prole. Cómo se redacta esto es evidentemente una cuestión de prudencia, vinculada con los amigos o enemigos morales -en la expresión de Engelhardt- que posea cada sociedad en concreto, pero lo más aconsejable es, en el caso de las universidades católicas o de inspiración católica, usar una frase general del estilo "los principios que informan". Lo mismo a la hora de enseñar estas verdades, en especial las que resultan crecientemente conflictivas. La prudencia, en este caso, consiste en (a) separar con toda claridad la acción considerada reprobable del agente concreto que la realiza, tal como hace por cierto el Catecismo de la Iglesia Católica, y (b) ofrecer un planteamiento académico y no partisano del tema, lo que supone analizar las razones a favor y en contra, y dar una respuesta fundada. Esto es uno de los requisitos de la libertad de cátedra: la emisión de opiniones científicamente fundadas, es decir, que puedan ser sustentadas superando el análisis de los expertos ${ }^{34}$.

Esta última consideración entronca con la pregunta anterior, a saber, ¿qué significa que los académicos deben "respetar" este núcleo doctrinal? Desde luego, no puede significar una restricción de la investigación. Esta prohibición sería contraria a la naturaleza misma del conocimiento, y contraria por lo tanto a la verdad y al procedimiento dialéctico del cual procede en la inteligencia humana, mediante afirmaciones científicamente sustentables. Esta conclusión se deduce de la fuente doctrinal por excelencia de las universidades católicas, Santo Tomás de Aquino, quien declara que el verdadero sabio consulta la experiencia de los demás que se encontraron ante los mismos y parecidos problemas, y que los oye con atención y respeto ${ }^{35}$. La conquista de la verdad -dice el mayor Doctor de la Iglesia- no es obra de un hombre solo, ni de una sola época, sino de toda la humanidad pensante a través de los siglos. Cada sabio o cada época contribuye con su grano de arena, y todos juntos constituyen el acervo de la ciencia y de la cultura de la Humanidad ${ }^{36}$. Y, a mayor abundamiento, agrega: "quien sinceramente busca la verdad no debe enojarse con ellos [los contradictores], sino tratarles con respeto y quedarles agradecido por lo que han contribuido, directa o indirectamente, al hallazgo o esclarecimiento de la verdad, única y suprema aspiración del sabio" ${ }^{37}$.

En un sentido estricto, la sustentabilidad apunta a que las opiniones académicas, para optar a la protección de la libertad de cátedra, deben alcanzarse en conformidad con

\footnotetext{
34 Metzger (1960) pp. 89-92.

35 Aquino, Santo Tomás, Sum. Theol., II-II, q.49, a.3, ad 2.

36 Aquino, Santo Tomás, In II Metaph, lect. 2, n. 276.

37 Aquino, Santo Tomás, In II Metaph, lect. 1, n. 287-8.
} 
estándares profesionales de investigación y análisis, determinados en principio por las reglas del arte y el uso de la comunidad científica en cada disciplina. Esta última dimensión del requisito puede ser controvertida, por cuanto algunas concepciones que se consideren mayoritarias podrían declarar sus parámetros metodológicos o sus bases axiomáticas como estándares imprescindibles para que determinadas opiniones fueran entendidas como científicamente sustentables, rechazando de ese modo las opiniones igualmente científicas de quienes no comporten sus puntos de partida. Por ejemplo, declarar un determinado problema como "resuelto", y censurar por lo tanto los argumentos contrarios a la "solución definitiva", por el solo hecho de ser opuestos a la mencionada opinio communis, sin apreciar su valor argumental. La opinión autorizada, según los parámetros antes mencionados, será más frecuente, como es de suponer, en el ámbito específico de investigación y docencia del académico, pero no excluye otras áreas del saber, por cuanto se entiende que un profesor universitario es capaz de realizar investigación en más de una dirección, la que será medida en su calidad a través del juicio metodológico de las conclusiones de su trabajo, estimado por los pares y por la comunidad científica. En otros términos: no se puede descalificar a priori el trabajo de un académico por razón de su matriz disciplinar; el valor argumental de su opinión será medido por los parámetros metodológicos utilizados, y ciertamente por el grado de verdad que contengan sus conclusiones. Esto quiere decir que, en principio, una Facultad no podría prohibir a académicos de otra distinta investigar o publicar sobre las materias que se adscriben al área disciplinar de la primera. Este debate es el que se presenta entre la competencia y la sobre-especialización dentro de las universidades, y afecta por supuesto a los estándares de libertad de los académicos ${ }^{38}$. Así pues, saber lo que piensan los demás constituye un medio imprescindible para conocer la verdad.

Tampoco el respeto al ideario puede consistir en que existan ciertos contenidos que no deban ser enseñados. Esto también sería contradictorio con la esencia de la universidad: ocultar o negar parte del proceso dialéctico de su adquisición, en el contraste con el error, por muy grave que éste sea. Es obligación seria de la universidad, según su capacidad y circunstancias concretas, enseñar los diversos aspectos de un problema, sin perjuicio de que acabe formulando la solución o respuesta que sea coherente con su ideario.

Ahora bien, si el respeto a los principios no consiste en dejar de estudiar ni en dejar de enseñar aquello que entra en conflicto con el ideario, ¿cuál viene a ser la naturaleza de la conducta que se exige de los profesores en este tipo de universidades? Para responder esta pregunta es interesante volver la vista nuevamente, por un momento, a la solución medieval. Ockham escribió en 1342 el tratado más sistemático y completo sobre la herejía de que se tuvo noticia en su tiempo: la primera parte del Diálogo entre el maestro y el alumno sobre las materias disputadas entre cristianos ${ }^{39}$. En este texto, Ockham asume siguiendo la tradición que la herejía no consiste solo en un asentimiento intelectual a una determinada proposición, sino que es necesario agregar la pertinacia como elemento esencial para la

\footnotetext{
38 BiedenKopf (2009) p. 805.

39 Oскнам (1962). Esta obra aborda especialmente el problema de la herejía papal. Ockham consideraba que el Papa Juan XXII (Aviñón) había caído en herejía al condenar oficialmente la afirmación franciscana de que Cristo y los apóstoles habían llevado una pobreza absoluta.
} 
configuración del tipo. Así pues, distingue tres tipos diferentes de herejía: (a) la que supone una negación casi literal de las verdades de fe, (b) un segundo tipo, tan obvio, que cualquier persona que comprenda cualquier cosa, incluso un iletrado, puede darse cuenta en qué sentido la afirmación contradice las Sagradas Escrituras, y (c) un tercero, consistente en la contradicción de lo que se dice en los libros sagrados, la cual resulta perceptible solo a los hombres de letras, que conocen bien los principios de la fe gracias un largo tiempo dedicado a su estudio y a su detallada reflexión. Este último es el que se denominó "herejía académica”. Podemos concluir de aquí que el disenso intelectual de las verdades de fe era considerado una especie de herejía, y por lo tanto, participaba de su elemento esencial: la obstinación, que atentaba contra la studiositas -la virtud esencial del mundo académico escolástico-. Si era concebible dentro de las aulas la posibilidad de una desviación en la búsqueda de la verdad, una desviación que llevara incluso a realizar afirmaciones contrarias a la ciencia de la salvación, evidentemente dicha acción debía encuadrarse en el ámbito del vicio correspondiente o correlativo a la virtud central de la vida académica y universitaria. Es decir, la herejía académica no podía encontrarse lejos de la curiositas. Quien más directamente abordó el problema de la curiositas académica fue Jean Gerson (1363-1429). En Contra vanam curiositatem in negotio fidei (1402), sostuvo que la curiositas es hija de la soberbia (superbia), y que produce un conocimiento opuesto a la sabiduría (sapientia). Pero la soberbia es el elemento central de la herejía, porque lo que caracteriza al hereje es el deseo de imponer la propia voluntad -manifestada en la obstinación en el error-, más que la ignorancia de la verdad. La obstinación en el error (pertinacia) y la presunción (presumptio), dice Gerson, son los elementos de la herejía ${ }^{40}$. Su difusión producía escándalo (scandalum), ponía en peligro el alma de todos aquellos que, vinculados con la universidad, pudieran oírlas, y corrompía la contribución de la cátedra universitaria a la configuración de una sociedad cristiana. Por eso, las doctrinas heréticas eran también consideradas peligrosas, no solo las herejías vulgares o comunes. La idea misma de curiositas sugiere la de una voluntad errática, entregada a una búsqueda de experimentación semejante a la que padecen los niños cuando están aburridos, y por lo tanto lejana al canon del orden y del trabajo productivo, sobre la base de una realidad sólida. La herejía formal estaba basada entonces en la obstinación consciente en el error. La hipótesis presentada a discusión era considerada errónea una vez que concluía el debate doctrinal, ya fuera por el valor mismo del argumento, o por la autoridad de la Iglesia, que declaraba su inadecuación con el dogma o la tradición. Así, una conclusión errónea podía convertirse en herética, por intervención del elemento voluntario, pero no necesariamente lo hacía. Solo entonces se consideraba que podía impedirse su difusión, no simplemente por causa de ser descartada como falsa en el proceso dialéctico-discursivo ${ }^{41}$.

\footnotetext{
40 ThIJSSEn (1998) pp. 1-2. Es importante revisar también Contra la curiosidad de los académicos de GERSON (1962) p. 222 ss.

41 Esto es lo que ocurrió con Giordano Bruno, a quién hasta el último momento se le ofreció la retractación, como consta en el acta de ejecución: "Giordano del quondam Giovanni Bruni; fraile apóstata de Nola di Regno, hereje impenitente. El qual (sic) fue exhortado con toda caridad por nuestros hermanos, y mandados llamar dos padres de santo Domingo, dos jesuitas, uno de la Chiesa Nova y uno de san Jerónimo, quienes con mucho afecto y doctrina le mostraron su error, estuvo hasta el fin en su maldita obstinación, dando vueltas en su intelecto y
} 
Así pues, el disenso académico no consistía en una conducta punible per se, sino que era considerado una parte o momento del debate académico, en medio de la Disputatio. Lo que convertía el disenso en herejía no era la investigación o seguimiento de una línea contraria al Magisterio, ni siquiera su enseñanza, pues consta el testimonio de profesores que enseñaron errores en el contexto de un debate, sin que por ello fueran recriminados o sancionados. El elemento central de lo inadmisible para la universidad medieval era la obstinación en el error, una vez que la autoridad académica y eclesiástica había hecho notar al académico esta circunstancia. Es decir, el mismo procedimiento que en la herejía vulgar.

Si traducimos esta concepción a nuestro tiempo, se hace más sencillo identificar de modo análogo qué se espera mediante la exigencia de "respeto" a los principios del ideario: la conducta que colisiona con las universidades así concebidas no es ni la investigación ni la enseñanza de la heterodoxia, sino la defensa manifiesta, reiterada y contumaz de opiniones que contradigan en materia grave la declaración de principios. Es decir, la intención manifiesta de combatir, desestabilizar y perjudicar las ideas matrices de la universidad. Estas personas, una vez que se les haya ofrecido de modo reiterado un cambio de actitud, si persisten en tal comportamiento, son las que efectivamente no pueden seguir formando parte de la universidad, y debe aplicárseles los términos del vínculo contractual-laboral. De manera ejemplar: en términos abstractos, un académico de una universidad con ideario puede tener una línea de investigación destinada a analizar los argumentos en favor del aborto. Puede publicar con toda libertad el fruto de sus reflexiones mediante libros, artículos científicos, o cualquier otro medio de difusión de las conclusiones de su trabajo. Puede por supuesto enseñar estos argumentos, comparándolos con los contrarios, y organizar cualquier actividad de extensión destinada a ofrecer explicaciones para un público más general. Todavía más: ese académico puede estar íntimamente convencido de que el aborto es un bien moral, y seguir siendo aceptado en una universidad que declare la inviolabilidad de la vida humana en cualquier estadio. Lo que probablemente no puede hacer es defender explícitamente el aborto, de manera reiterada o militante, a través de los diversos medios de difusión antes mencionados, u otros cada más usuales para el académico contemporáneo, como entrevistas en los medios de comunicación o redes sociales.

Todas estas conductas, por supuesto, deben ser apreciadas de modo prudencial, teniendo en cuenta el bien afectado y el mal que eventualmente se puede causar mediante la difusión de doctrinas contrarias al ideario, y el escándalo que esto puede producir en las personas vinculadas con la universidad. Por esto es importante que los rectores encarguen constantemente a los decanos tener siempre presente el ideario y el objeto final de la universidad, vinculado justamente con la difusión de la verdad en las materias más relevantes, según se explicaba antes. Es preciso generar una conciencia en la comunidad universitaria sobre la importancia de respetar el ideario. Para esto, es aconsejable que la mayoría de los

su cerebro con mil errores y vanidades. Y tanto perseveró en su obstinación que fue conducido por los ministros de justicia a Campo di Fiori, y allí se le desnudó y fue atado a un palo y quemado vivo, acompañado siempre de nuestra Compañía que cantaba letanías, y los confortantes lo atendían hasta último momento para que abandonara su obstinación, con la que al final acabó su miserable e infeliz vida”. Véase BENAVENT (2004) pp. 106-7. 
profesores no solo respete dicho ideario (es decir, no defienda doctrinas contrarias a él), sino que también lo comparta activamente.

\section{EL REQUiSITO CONTRACTUAL}

Esta idea del respeto al ideario exigido a todos los académicos no atenta contra el derecho a la libertad de cátedra considerada en abstracto, porque no limita ni la libertad de investigación ni la libertad de docencia, según hemos revisado antes (luego habrá que revisar la configuración positiva en cada caso concreto, atendiendo a la letra de los diversos ordenamientos jurídicos), y porque no se define de modo sectario contra cualquier otra realidad humana o secular ${ }^{42}$. Es decir, la restricción no atenta materialmente, en principio, contra la libertad de los académicos, porque lo que se les prohíbe es el proselitismo de las ideas opuestas, no su consideración estrictamente científica. En estricto sentido, ningún académico de ninguna universidad, incluso sin ideario, es contratado con la intención de que use a la universidad como medio de una determinada causa.

Pero supongamos que un académico, en uso de su libertad de investigación, llega honestamente a la conclusión de que -para seguir con el ejemplo- el aborto es un derecho de la mujer. Supongamos también que no hace activismo abortista, no tiene una actitud militante, y se limita a ofrecer las razones en favor de la interrupción voluntaria del embarazo. Imaginemos también que la autoridad le ha comentado en reiteradas ocasiones que esta opción contradice el ideario, en la medida en que sus argumentos ofrecen apoyo para la consolidación de la posición en comento. ¿Podría ser desvinculado de la universidad también en este caso? Los partidarios de esta opción dirán que la razón directa que se debe esgrimir es no solo la contradicción material con los principios de las referidas conclusiones a las que ha llegado -como horizonte hermenéutico-, sino el incumplimiento de lo estipulado en el contrato laboral, por el que se ha comprometido previamente a "respetar" dicho ideario, es decir, a no combatirlo.

La existencia efectiva de universidades con ideario en un determinado sistema jurídico dota de capacidad jurídica, al mismo tiempo, a su actuación, es decir, el desarrollo de todas las acciones tendentes a la consecución de sus objetivos estatutarios, porque si no fuera así, su existencia carecería de sentido. La universidad tiene tanto el derecho como el deber de promover el ideario ${ }^{43}$, porque de otra forma no es funcional al bien común ni al Estado de Derecho, que la dota normativamente de existencia. En este punto es fuerte el argumento de la libertad religiosa, para aquellas universidades a las que competa. Si existe la libertad religiosa, las personas que comparten esa religión tienen que poder asociarse en instituciones intermedias que representen ese credo. Entre ellas, sin duda alguna cabe la posibilidad de fundar universidades, porque la universidad y en general las instituciones del conocimiento son la traducción social del uso común de la inteligencia. Y siendo la inteligencia la facultad más propia del hombre, es evidente que, después de las instituciones propias del culto y de la actividad pastoral, el primer cuerpo intermedio que una fe religiosa debe poder fundar son centros universitarios. Además, como negar la libertad religiosa

\footnotetext{
42 Curran (1997) p. 92.

43 Así también la Sentencia del Tribunal Constitucional Español No 106/1996, de 12 de junio.
} 
es prácticamente imposible en un contexto donde se reclama la superioridad absoluta de la conciencia individual, resulta que este punto es de hecho casi indiscutible.

Al tener la obligación de promover su ideario, la universidad debe disponer necesariamente de las atribuciones jurídicas para hacerlo. Esto significa, entre otras cosas, la posibilidad de generación de un estatuto particular para sus profesores, distinto o más específico del que puede caber en las universidades denominadas confusamente "neutrales", que sea coherente con sus objetivos propios, cuyo desarrollo es justamente lo que justifica su existencia. Es en este contexto donde su sitúa el acuerdo contractual de "respetar" el ideario. El profesor, que para estos efectos es un trabajador, no puede realizar acciones que terminen por dificultar o impedir la promoción del ideario, e incluso, dependiendo de las características de la plaza, puede verse obligado a sujetar ámbitos de su vida privada a patrones de conducta acordes con el ideario ${ }^{44}$. Sin lugar a dudas, el profesor no es un empleado, en un sentido puramente vertical-administrativo ${ }^{45}$. Esta discusión se planteó con intensidad en la universidad alemana del siglo XIX, en que todos los académicos tenían el estatuto de empleados del Estado, y por lo tanto podían ser despedidos en cualquier momento. El concepto de Lehrfreheit- se refería justamente al derecho legalmente reconocido de los profesores ordinarios y asociados, considerados en cuanto empleados del gobierno (por desempeñarse en una institución del Estado), para realizar sus tareas académicas fuera de la línea de mando burocrática que afectaba al resto de los empleados de la administración pública, es decir, con un cierto grado de discrecionalidad con el cual el resto de los empleados públicos no contaban. La libertad de cátedra implicaba un margen de autonomía administrativa concedida a los profesores por causa de la importancia comparativa de su labor dentro del contexto de la burocracia estatal, sin que ella alterara en ningún sentido su estatuto funcionario.

En la base del contrato con cláusula de ideario se encuentra la libertad de quien decide integrarse a la institución, y, por tanto, opta libremente por obligarse a determinados deberes propiamente laborales e incluso extra laborales, de tal modo que se podría incluso presumir que comparte la declaración de principios. En este caso, no se le obligaría a comportarse de determinada manera, e incluso se podría afirmar que el ejercicio de sus derechos no sufre modulación alguna; más bien se produciría una coincidencia en el modo en que venía ejerciendo determinados derechos o cumpliendo determinados patrones de conducta antes de ser contratado, y el ajustamiento exigido a determinados derechos en una relación laboral. Esto supone que efectivamente no se estaría "laboralizando" la vida privada del trabajador, y que el incumplimiento de sus deberes con el ideario tendría como consecuencia sanciones para el académico, que pueden llegar incluso al despido del docente, sin que pueda ser calificado de despido nulo ${ }^{46}$.

Solo a la luz de las circunstancias del caso concreto, finalmente, es posible llegar a definir con precisión el contenido concreto del deber de respeto al ideario y el alcance de las modulaciones que puedan sufrir los derechos de los trabajadores en una institución que posea una declaración de principios. Como criterio general se puede decir, sin embargo,

\footnotetext{
44 Castillo (2006) p. 304.

45 RÜEgG (2004) p. 8

46 Castillo (2006) pp. 306-7.
} 
que los derechos del titular del centro de enseñanza y el derecho del académico, están llamados a convivir en paz, modulándose mutuamente. Esto significa que, en el caso concreto, el contenido del derecho del titular del centro no puede ser interpretado de tal modo que desconozca el contenido del derecho del trabajador, docente o no, ni tampoco a la inversa. El primer criterio trae consigo un segundo. La vigencia del ideario, como manifestación del derecho del titular del centro, así como la prestación laboral contratada, deben ser los principales puntos de referencia para determinar tanto el concreto deber de respeto al ideario, los derechos del académico que podrán ser modulados, y el alcance de las modulaciones; así como las consecuencias que se puedan generar por el ejercicio indebido que pueda hacer de sus derechos el trabajador ${ }^{47}$.

\section{REFLEXIÓN FINAL}

El papel de las universidades con ideario parece ser pues relevante en una sociedad democrática, de lo que se sigue que es necesario preservarlas institucionalmente, y dotar a sus académicos de la libertad necesaria para ejercer su labor. La razón para concluir esta necesidad tiene en mi opinión un doble aspecto. Por una parte (a), las comunidades complejas, como las sociedades del siglo XXI, profundamente interconectadas y globales, requieren de caminos institucionales para expresar la diferencia intrínseca que supone la globalización en un mundo tan intensamente vinculado; es necesario canalizarla, instituirla, para darle carta blanca en la comunidad como es debido. La existencia "política" de las diferencias fortalece la co-existencia democrática de las comunidades diversas y altamente desarrolladas, así como la naturaleza de su discurso público, porque es el factor que permite tender puentes, crear vínculos, modelar y resolver las contradicciones a través del diálogo y no de la violencia, del Derecho y no del poder del más fuerte. Justamente uno de los grandes logros de nuestro tiempo ha sido la conquista del discurso como ámbito apropiado para la localización de los conflictos. Hoy los inmensos medios tecnológicos entregan la capacidad de aumentar exponencialmente el poder, por lo que el fortalecimiento del Derecho a través de la canalización institucional de las diferencias adquiere un papel todavía más preponderante que en el pasado.

Si bien no siempre y en todos los casos es posible evitar un conflicto violento mediante los instrumentos propiamente discursivos de la democracia -los seres humanos no siempre escogen el bien superior, aunque lo comprendan con claridad-, existe una especie de consenso formal-universal entre los pueblos civilizados de que las diferencias, al ingresar en un proceso de discusión dialéctica, fortalecen el discurso público y reemplazan el uso de la fuerza física por el análisis crítico y el consenso fundado, robusteciendo de ese modo las instituciones políticas y jurídicas. Desde esta perspectiva, es inherente a la democracia la puesta en juego de las diferencias a través del escrutinio por parte de la razón pública de los asuntos debatidos, lo que implica al mismo tiempo la valoración de la diferencia, y refuerza la necesidad de expertos preparados para hacerse cargo de los distintos aspectos que surgen de la multiplicidad de visiones. Este argumento, que tiene un contenido procesal, justifica

47 Castillo (2006) p. 308. 
la existencia de centros como las universidades objeto de este trabajo, ya que ellas no solo canalizan el pensamiento que les es propio a través de instituciones abiertas a la sociedad civil, sino que además producen un buen número de expertos en todos los campos, capaces de desplegar y debatir con solvencia las ideas que defienden, enriqueciendo de este modo la naturaleza del debate público.

Por otro lado (b), las universidades con ideario que expresan un compromiso religioso, y específicamente las católicas, se inclinan a desarrollar como parte de su objetivo principal un aspecto del conocimiento humano que se encuentra excluido de las instituciones supuestamente "neutrales": la relación entre el conocimiento científico y el conocimiento de fe. La importancia de esta dimensión se advierte en la necesidad de la fe para la vida humana, ya sea en sentido teológico o puramente natural. En otros términos: es un mecanismo esencial para dar curso a la necesidad de trascendencia del espíritu humano, pero también para vivir en el mundo cotidiano, pues sería imposible comprobar la veracidad de todas las afirmaciones y supuestos con que lidiamos a cada momento. Y en sentido opuesto: una explicación sobre el conocimiento humano que elimine el papel cognoscitivo de la fe, y se centre exclusivamente en la racionalidad causal-empírica, tendrá grandes dificultades para explicar sin distorsionar el fenómeno humano de modo integral y sintético. En este sentido, el aporte de este tipo de universidades entrega un elemento necesario para la reflexión integral del sentido y significado de la humanidad. Al desplegar los variados confines y aspectos de la interacción entre la fe y la razón, estas universidades representan además la posibilidad de abordar en el discurso público determinadas preguntas que posiblemente no llegarían a plantearse desde una óptica puramente ilustrada, satisfaciendo con ello las inquietudes de una parte no despreciable de la población. La dialéctica ciencia-fe constituye además por sí solo un ámbito intelectual muy relevante en la historia del pensamiento universal en todas las culturas, y parece en consecuencia razonable que esté presente en la configuración del discurso público de nuestras sociedades contemporáneas, aunque parte de ellas declare carecer de fe desde un punto de vista personal.

Para poder desarrollar los diversos aspectos metodológicos y científicos en que se encuentran la fe y la razón, los académicos y expertos en cada campo de este tipo de universidades deben disponer de libertad de cátedra, si por ella se entiende la posibilidad de seguir el curso de su razonamiento, formular las conclusiones y darlas a conocer. En este procedimiento, la autonomía intelectual de los profesores se ve iluminada por un horizonte de significado, un criterio hermenéutico que deriva de la fe que profesan y de los principios racionales coherentes con ella. Tal paradigma de sentido otorga un curso de razonamiento que es imposible al margen de dicho horizonte de significado. Así pues, las universidades con ideario religioso deben poner cuidado en animar a sus diversos estamentos para tener presente dicho ideario, buscarlo consciente y diariamente en el ejercicio de la actividad académica, y exigir que se respete cuando los integrantes de la comunidad universitaria no lo comparten.

\section{BIBLIOGRAFÍA CITADA}

Altbach, Philip (1999): "The Logic of Mass Higher Education", Tertiary Education and Management, vol. 5, № 2: pp. 107-24. 
Aquino, Santo Tomás: Summa Theologiae, en Corpus Thomisticum. Subsidia studii ab Enrique Alarcón collecta et edita: www.corpusthomisticum.org.

Aquino, Santo Tomás: In II Metaph, en Corpus Thomisticum. Subsidia studii ab Enrique Alarcón collecta et edita: www.ciorpusthomisticum.org.

Andreescu, Liviu (2008): "Academic Freedom and Religiously-Affiliated Universities", Journal for the Study of Religions and Ideologies, vol. 7, No 19: pp. 162-183.

BAUdrillard, Jean (1987): El otro por si mismo (Barcelona, Anagrama, tercera edición).

BARCIA, Roque (1950): Gran diccionario de sinónimos castellanos (Buenos Aires, Joaquín Gil Editor).

Benavent, Júlia (2004): Actas del proceso de Giordano Bruno (Valencia, Els debats de debats).

Biedenkopf, Kurt (2009): "Fulfilling the Promise of Academic Freedom", Social Research, vol. 76, No 3: pp. 805-810.

Castillo Córdova, Luis (2006): La libertad de cátedra en la relación laboral con ideario (Valencia, Editorial Tirant lo Blanch).

Classen, Peter (1981): "Zur Geschichte der 'Akademische Freiheit', vornehmlich im Mittelalter", Historische Zeitschrift, vol. 232, No 3: pp. 529-553.

Curran, Charles E. (1997): "The Catholic Identity of Catholic Institutions”, Theological Studies, vol. 58: pp. 90-108.

Deleuze, Gilles (2014): El poder. Curso sobre Foucault, Volumen II (Buenos Aires, Editorial Cactus).

DerridA, Jacques (2003): De la gramatología (Buenos Aires, Editorial Siglo XXI).

DeWey, John (1902): “Academic Freedom”, Educational Review, vol. XXIII: pp. 1-14.

Fairclough, Norman (2003): "Political Correctness'. The Politics of Culture and Language", Discourse \& Society, No 14: pp. 17-28.

Foucault, Michel (2007): Historia de la sexualidad, la voluntad de saber (México, Editorial Siglo XXI, trigésimoprimera edición).

Furner, Mary O. (1975): Advocacy \& Objectivity. A Crisis in the Professionalization of American Social Science, 1865-1905 (Lexington, The University Press of Kentucky).

Gerson, Jean (1962): Contra la curiosidad de los académicos, en Glorieux, Palemon (edit.), Oeuvres Complètes, Tomo III (París, Descleé y Cie) pp. 222-249.

Habermas, Júrgen (1993): El discurso filosófico de la Modernidad (Madrid, Taurus).

Hollinger, David A. (1987): “The Knower and the Artificer", American Quarterly, vol. 39, No 1, special issue: Modernist Culture in The Human Sciences, p. 37-55.

Ingram, Larry C. (1986): "Sectarian Colleges and Academic Freedom", Review of Religious Research, vol. 27, No 4: pp. 300-14.

KeYes, Ralph (2004): The Post-Truth Era: Dishonesty and Deception in Contemporary Life (Nueva York, Saint Martin's Press).

LeE, Philip (2015): Academic Freedom at American Universities. Constitutional Rights, Professional Norms and Contractual Duties (Maryland, Lexington Books).

MAdrid, Raúl (2018): “¿Existe todavía el derecho a la libertad de cátedra?”, Revista de Derecho (Valdivia), vol. XXXI, No 1: pp. 32.

Metzger, Walter P. (1960): Academic Freedom in the Age of the University (Nueva York, Columbia University Press). 
Metzger, Walter (1978): "Academic Freedom and Scientific Freedom”, Daedalus, vol. 17, No 2: pp. 93-114.

Newman, John Henry (2016): La idea de una universidad (trad. Paula Jullian, Santiago, Ediciones Pontificia Universidad Católica de Chile, Santiago).

Ocкнам, Guillermo de (1962): Opera Plurima, vol. I, Dialogus de imperio et pontificia potestate (Londres, Gregg Press).

Paulsen, Friedrich (1906): The German Universities and University Studies (trad. Frank Thilly y William W. Elwang, Nueva York, Charles Scribner's Sons).

PeŃA, Carlos (2018): “Exposición”, en Madrid, Raúl (edit.), Libertad de cátedra antigua y moderna (Santiago, Editorial ResPública), pp. 105-15.

Philp, Mark (1983): "Foucault on Power: A Problem in Radical Translation?”, Political Theory, vol. 11, No 1: pp. 29-52.

Rodríguez Coarasa, Cristina (1998): La libertad de enseñanza en España (Madrid, Tecnos).

RÜEGG, Walter (2004): “Themes”, en RÜEGG, Walter (edit.), A History of the University in Europe, vol. III: Universities in the XIX and Early XX Centuries (Cambridge, Cambridge University Press), pp. 3-32.

Simon, Robert L. (1972): "The Concept of a Politically Neutral University", en Held, V., Nielsen, K. y Parsons, C. (edits.), Philosophy and Political Action. Essays edited for the New York Group of the Society for Philosophy and Public Affairs (Nueva York, Oxford University Press) pp. 217-33.

Thijssen, J.M.M.H. (1998): Censure and Heresy in the University of Paris. 1200-1400 (Filadelfia, University of Pennsylvania Press).

Tsvetrova, Natalia (2013): Failure of American and Soviet Cultural Imperialism in German Universities, 1945-1990 (Leiden, Brill).

\section{JURISPRUDENCIA CITADA}

Sentencia del Tribunal Constitucional Español No 106/96, de 12 de junio.

\section{DOCUMENTOS UNIVERSITARIOS}

Declaración De Principios. Pontificia Universidad Católica de Chile. Disponible en: https://www12.uc.cl/FormPostul/plantillas/smi_declaracion.pdf. Fecha de consulta: 18 de febrero de 2019.

1915 Declaration of Principles. American Association of University Professors (AAUP). Disponible en: http://www.aaup-ui.org/Documents/Principles/Gen_Dec_ Princ.pdf. Fecha de consulta: 18 de febrero de 2019.

Chichgo Principles: Report of the Committee on Freedom of Expression. University of Chicago. Disponible en: https://freeexpression.uchicago.edu. Fecha de consulta: 18 de febrero de 2019. 
MADRID RAMírez, Raúl — "La libertad de cátedra de las universidades con ideario religioso: objeciones y respuestas"

\section{DOCUMENTOS ELECTRÓNICOS}

Korn, Sandra (2014): The Doctrine of Academic Freedom. Disponible en: http://www.thecrimson.com/column/the-red-line/article/2014/2/18/academic-freedom-justice/? Fecha de consulta: 2 de mayo de 2020.

Mochón, Juan Antonio (2019): La democracia exige y necesita una universidad laica. Disponible en: https://laicismo.org/la-democracia-exige-y-necesita-una-universidad-laica/. Fecha de consulta: 10 de junio de 2020. 